\title{
POTENSI WILAYAH SEKITAR PANTAI SELATAN KABUPATEN \\ LEBAK PROVINSI BANTEN DALAM MENDUKUNG \\ PEMBANGUNAN PARIWISATA
}

\author{
M.H. Dewi Susilowati ${ }^{1}$
}

Email: maria.hedwig@ui.ac.id

\begin{abstract}
Abstrak: Pantai selatan Kabupaten Lebak sebagian telah dikembangkan sebagai obyek wisata, namun hingga saat ini belum sepenuhnya dapat menarik wisatawan domestik maupun internasional. Dalam pembangunan pariwisata diperlukan dukungan penduduk dan aktivitasnya, serta aksesibilitas yang berada di sekitar pantai. Tujuan penelitian ini yaitu untuk mengetahui potensi wilayah sekitar pantai selatan Kabupaten Lebak. Metode analisis yang digunakan dalam penelitian ini adalah analisis faktor (factor analysis) yang diekstraksi dengan analisis komponen utama (Principal component analysis/ PCA) untuk menganalisis potensi wilayah sekitar pantai selatan Kabupaten Lebak dan analisis keruangan (spatial analysis) dengan menggunakan peta untuk pengembangan pariwisata. Hasil yang diperoleh menunjukan bahwa potensi wilayah antar desa bervariasi, namun sebagian besar merupakan desa yang didominasi oleh penggunaan lahan perkebunan, jumlah dan kepadatan penduduk rendah hingga sedang, pendidikan penduduk didominasi oleh pendidikan dasar, mata pencaharian didominasi oleh petani dan buruh tani, aksesibilitas relatif sedang hingga rendah. Secara spasial menunjukkan pengembangan pariwisata lebih diprioritaskan di bagian timur pantai selatan Kabupaten Lebak seperti Desa Sawarna Kecamatan Bayah, yang letaknya lebih dekat dengan pantai Pelabuhanratu Sukabumi yang lebih berkembang dan mempunyai variasi atraksi pariwisata.
\end{abstract}

Kata Kunci : Geografi Potensi Wilayah, Pariwisata Pantai, Lebak

\section{PENDAHULUAN}

Potensi wisata alam dalam suatu wilyah, seringkali belum diandalkan sebagai sesuatu aset yang mampu mendatangkan pendapatan daerah. Masih banyak potensi obyek wisata yang belum dimanfaatkan secara maksimal, padahal wisata alam terbukti dapat dapat mendatangkan pendapatan yang cukup besar, membuka peluang usaha dan kerja serta tetap dapat berfungsi menjaga kelestarian alam (Gavilan, M.Dolores Sarrion et al, 2015;
Atkinson, Doreen, 2016; Biddulph, Robin, 2015) .

Pariwisata sebagai industri jasa yang mempunyai peranan penting dalam menetapkan kebijakan tentang kesempatan kerja. Hal ini didasarkan pemikiran bahwa permintaan kesempatan kerja yang permanen merupakan faktor yang perlu dipertahankan, karena permintaan perjalanan wisata selalu akan meningkat dalam waktu yang panjang. Pada saat ini industri pariwisata 
106

M.H. Dewi Susilowati. Potensi Wilayah Sekitar Pantai Selatan Kabupaten Lebak Provinsi Banten Dalam Mendukung Pembangunan Pariwisata

mengalami kemajuan yang pesat, sudah seharusnya memanfaatkan semua potensi yang ada dengan sebaik-baiknya, dan dengan demikian diharapkan dapat membangkitkan pembangunan di daerah (Zaidah, Esmat, 2016; Zakaria, Faris, 2014; Vitasurya, Vincenti Reni. 2015; Fatimah, Titin. 2015; Akdag, Gurhan \& Zafer Oter, 2011)

Pembangunan pantai sebagai tempat wisata bagi masyarakat mengharuskan pengelolaan lingkungan secara baik, karena pawisisata menuntut kebersihan lingkungan yang sangat tinggi dan peningkatan pendapatan masyarakat di sekitarnya (Nawawi, Ahmad, 2013, Obonyo, George Otieno \& Erick Victor Onyango Fwaya, 2012)

Pantai Lebak dan wilayah sekitarnya mempunyai potensi daya tarik wisata domestik maupun internasional. Variasai atraksi yang tersedia meliputi pantai, laut, batuan karang, bukit, rimba lindung dan goa. Salah satu atraksi yaitu pantai Ciantir dengan barisan pasir putih serta jejeran pohon kelapa dan ombak laut yang menarik perhatian. Wilayah sekitar pantai selatan Kabupaten Lebak didominasi oleh penggunaan lahan pertanian dan sebagian besar belum dimanfaatkan secara intensif, kuantitas dan kualitas penduduk reltif rendah Susilowati. MH Dewi, Tuty H, Ratna S, 2012 dan 2013). Peningkatan produktifitas dan perbaikan kualitas produk termasuk pengembangan produk pariwisata merupakan faktor yang sangat strategis. Perbaikan dan modernisasi teknologi merupakan isu yang sangat krusial yang harus diupayakan secara sungguh-sungguh untuk mendorong proses peningkatan pendapatan masyarakat Ajala OA \& Aliu IR, 2013; Gruber, Denis, 2008).

Berdasarkan latar belakang tersebut, maka tujuan penelitian ini adalah (a) menganalisis potensi wilayah sekitar pantai selatan di Kabupaten Lebak; (b) sesuai potensi wilayah tersebut, diperoleh wilayah pengembangan pariwisata pantai yang berada di Kabupaten Lebak

\section{METODE PENELITIAN}

Dalam penelitian ini menggunakan data citra yang diperoleh dari google earth dan peta rupa bumi untuk mengetahui penggunaan tanah dan jaringan jalan Kabupaten Lebak. Sedangkan data kondisi sosial ekonomi diperoleh dari BPS. Pengolahan data dilakukan dengan cara: (a) mengklasifikasikan data menjadi dua kelompok, yaitu data kuantitatif dan kualitatif; (b) mengolah data spasial dan tabular dengan teknologi Sistem Informasi Geografis (SIG) dan Penginderaan Jauh (PJ); (c) data kuantitatif diolah dengan program SPSS (Statistical Product and Service Solotions). Analisis keruangan (spatial analysis) dan analisis faktor (factor analysis) yang diekstraksi dengan analisis komponen utama (Principal component analysis/ PCA) untuk menganalisis potensi wilayah di Kabupaten Lebak. Menurut Johnson (1987), dengan melakukan analisis komponen utama secara tidak langsung sudah melakukan analisis geografi yaitu melakukan identifikasi kelompok variabel terkait, termasuk overlap antar kelompok yang terjadi ketika variabel mempunyai hubungan yang lebih tinggi dari 
komponen lain. Bentuk umum model analisis faktor adalah sebagai berikut :

$$
\mathrm{Xp}=\mathrm{Ap} 1 \mathrm{CF} 1+\mathrm{Ap} 2 \mathrm{CF} 2+\ldots . .+
$$
$\mathrm{ApmCFm}+\mathrm{U}$

$\mathrm{CFm}$ : common factor ke-m, yang dibentuk dari sejumlah variabel. Disebut common factor karena seluruh variabel dapat ditampilkan sebagai fungsi dari common factor

$\mathrm{Up}$ : unique factor dalam variabel ke-p, yaitu bagian variabel yang tidak dapat dijelaskan oleh common factor. Unique factor diasumsikan tidak berkorelasi satu sama lain dan juga tidak berkorelasi dengan common factor.

Apm : konstanta yang digunakan untuk mengkombinasikan sejumlah $\mathrm{m}$ faktor, juga disebut factor loading.

\section{HASIL}

\section{Kondisi Penduduk}

Wilayah sekitar pantai selatan Kabupaten dalam penelitian meliputi 6 kecamatan yang berbatasa langsung dengan laut, luas daerah $75.785 \mathrm{Ha}$ yang terdiri dari 68 desa. Kecamatan paling luas wilayahnya adalah Kecamatan Panggarangan (17.715 Ha) dan yang paling sempit wilayahnya adalah Kecamatan Cilograng (9.602 Ha). Sedangkan desa yang terluas adalah .Desa Jatake (3639,09 Ha) dan tersempit Desa Gunungbatu (186,14 Ha).

Jumlah penduduk di daerah penelitian sebanyak 262.242 jiwa, terdiri dari laki-laki 135.323 jiwa dan perempuan 126.919 jiwa. Jumlah penduduk terbanyak di desa Muara (10.782 jiwa) dan paling sedikit Desa Sawarna Timur (1835 jiwa). Kepadatan penduduknya secara umum rendah (3 jiwa/ha, kepadatan penduduk tertinggi (25 jiwa/ha) terdapat di Desa Malingping Utara dan terendah (1 jiwa/ha) adalah desa Sogong dan Jatake (Kecamatan Panggarangan).

Pendidikan penduduk bervariasi, namun masih di dominasi oleh penduduk berpendidikan dasar, yakni SD dan SMP. Persentase penduduk yang mempunyai tingkat pendidikan Sarjana, sebagian besar terdapat di desa Bayah Barat (513 orang), Kecamatan Bayah. Mata pencaharian penduduk sebagian besar petani, bahkan pada Desa Mekarsari dan Desa Pondok Panjang lebih dari $90 \%$ penduduknya sebagai petani. Penduduk yang bekerja sebagai pedagang yang terbanyak berada di Desa Malingping Selatan $(>30 \%)$.

\section{Penggunaan Tanah}

Penggunaan tanah di daerah penelitian dapat dibedakan menjadi penggunaan tanah permukiman, perkebunan, sawah, semak, tegalan dan hutan. Daerah sekitar pantai masih didominasi oleh penggunaan tanah perkebunan (59 $\%$ ), sedangkan permukiman hanya 3,27 $\%$, penggunaan tanah sawah dan hutan mempunyai persentase yang tidak jauh berbeda yaitu $19.41 \%$ untuk hutan dan sawah $15 \%$.

Persebaran perkebunan hampir merata di seluruh daerah, sedangkan permukiman berpusat di bagian barat yaitu di Desa Cilangkahan dan Malingping Selatan, Sementara itu sawah mengelompok di bagian barat yaitu di Kecamatan Wanasalam dan Malingping. Persebaran hutan mendominasi bagian timur yaitu di desa-desa termasuk Kecamatan Cilograng. 
108

M.H. Dewi Susilowati. Potensi Wilayah Sekitar Pantai Selatan Kabupaten Lebak Provinsi Banten Dalam Mendukung Pembangunan Pariwisata

Penggunaan tanah sawah irigasi meliputi 10.318,09 ha, sedangkan sawah tadah hujan tidak terdapat di daerah sekitar pantai. Persebaran per desa sawah irigasi di dominasi oleh Desa Cisarap, Kecamatan Wanasalam seluas 1.295,99 ha, Desa Bolang, Kecamatan Malingping seluas 968,47 ha. Penggunaan tanah semak belukar yang terluas terdapat di Desa Senanghati, Kecamatan Malingping seluas 316,97 ha, Desa Sukatani, Kecamatan Wanasalam seluas 303,35 ha. Hutan terluas terdapat di Desa Jatake Kecamatan Panggarangan seluas 2.095,76 ha, yang letaknya di bagian timur.

\section{Jaringan Jalan}

Jalan di daerah penelitian terdiri atas jalan arteri, kolektor dan jalan lokal. Tidak semua desa memiliki jalan arteri, hanya di sepanjang pantai selatan yang memiliki jalan arteri. Kerapatan jalan di daerah penelitian diklasifikasikan kedalam tiga kelas yaitu kurang dari $15 \mathrm{~m} / \mathrm{ha}$, antara $15-30 \mathrm{~m} / \mathrm{ha}$ dan lebih dari $30 \mathrm{~m} / \mathrm{ha}$. Desadesa yang mempunyai jalan yang paling rapat adalah Desa Malingping Utara di Kecamatan Malingping.

\section{PEMBAHASAN}

\section{Potensi Wilayah}

Berdasarkan hasil ekstraksi faktor menunjukkan bahwa dari 14 variabel yang dianalisis didapatkan 4 faktor utama yang memiliki eigenvalues $>1$. Keempat faktor tersebut memiliki kontribusi sebesar 70,9 \% dari variansi total. Sedangkan hasil rotasi faktor menunjukkan variabelvariabel yang menjadi anggota masingmasing factor utama. Menurut Johnson
(1987), Syarat suatu variabel untuk menjadi anggota salah satu faktor utama adalah memiliki loading factor > 0,5 (harga mutlak).

Faktor-faktor utama disusun berdasarkan perannya, sehingga terlihat bahwa faktor 1 merupakan faktor terpenting dibanding dengan factor lainnya, yaitu sebesar 26,71\% dalam membentuk potensi wilayah. Kontribusi masingmasing faktor dijadikan bahan pertimbangan dalam menentukan potensi wilayah. Dalam menentukan potensi wilayah digunakan nilai scor factor positif dan negatif (Susilowati, MH Dewi, Ratna S, Tito LI, 2009). Jika desa yang mempunyai nilai score faktor positif, berarti nama potensi terbentuk oleh faktor utama tersebut. Dengan memperhatikan karakter masing-masing faktor utama, maka potensi wilayah terdiri dari empat potensi.

Potensi I pembentuk utamanya adalah perkebunan dan penduduk merupakan desa yang didominasi oleh perkebunan, jumlah dan kepadatan penduduk rendah, pendidikan penduduk didominasi oleh pendidikan dasar, mata pencaharian didominasi oleh petani dan buruh tani, akses relatif sedang hingga rendah. Wilayah potensi I mendominasi wilayah sekitar pantai selatan Lebak, yang menyebar dari barat sampai pantai.

Potensi II pembentuk utamanya sawah irigasi, merupakan desa yang didominasi oleh Sawah irigasi, jumlah dan kepadatan penduduk sedang, pendidikan penduduk didominasi oleh pendidikan dasar, mata pencaharian didominasi oleh petani, akses relatif sedang hingga rendah. sedangkan potensi II berada di sekitar pantai barat, seperti Desa Cisarap, Kecamatan Wanasalam 
dan Desa Bolang, Kecamatan Malingping.

Potensi III pembentuk utamanya hutan, merupakan desa yang didominasi oleh hutan, jumlah dan kepadatan penduduk rendah hingga sedang, pendidikan penduduk didominasi oleh pendidikan dasar, mata pencaharian didominasi oleh petani dan buruh tani. akses relatif sedang hingga rendah. Wilayah Potensi III cenderung terkonsentrasi di timur, seperti Desa Jatake Kecamatan Panggarangan.

Potensi IV tidak ada pembentuk utamanya, merupakan desa yang tidak mempunyai cirri khusus, jumlah dan kepadatan penduduk rendah hingga sedang, pendidikan penduduk didominasi oleh pendidikan dasar, mata pencaharian didominasi oleh petani dan buruh tani, akses relatif sedang hingga rendah. Wilayah potensi IV yang tidak mempunyai cirri khusus, menyebar secara acak, ke semua arah.

\section{Pengembangan Pariwisata}

Dilihat dari potensi wilayah antar desa di sekitar pantai selatan Kabupaten Lebak, sebagian besar merupakan desa yang didominasi oleh perkebunan, jumlah dan kepadatan penduduk rendah hingga sedang, pendidikan penduduk didominasi oleh pendidikan dasar, mata pencaharian didominasi oleh petani dan buruh tani, aksesibilitas relatif sedang hingga rendah. Menurut Burton, (2005) maupun Yoeti ,H. Oka A. (2000) Unsur utama yang menarik pengunjung ke daerah pariwasata adalah fasilitas primer (atraksi alam maupun buatan), fasilitas sekunder (akomodasi, koliner, sovenir), fasilitas kondisional (aksesibilitas, parkir, toilet, tempat ibadat).

Fasilitas primer yang paling bervariasi di wilayah sekitar pantai selatan terdapat di Desa Sawarna, Kecamatan Bayah. Variasai atraksi yang tersedia meliputi pantai, laut, batuan karang, bukit, rimba lindung dan goa. Salah satu atraksi di Desa ini yaitu pantai Ciantir dengan barisan pasir putih serta jejeran pohon kelapa dan ombak laut yang menarik perhatian. Pantai ini relatif lebih banyak dikunjungi oleh wisatawan yang datang, dibandingkan dengan lokasi pantai lainnya.

Pantai tanjung layar juga memberikan kesejukan untuk semua orang yang memandangnya. Bentangan karang melingkari pantai ini, dengan 2 karang yang menjulang tinggi ke atas serta jadi ikon dari Sawarna. Nama pantainya adalah Sawarna, ada di suatu desa pesisir yang mempunyai beragam jenis tempat wisata, menarik untuk dikunjungi seperti pantai, sungai, rimba, panjat tebing, gua, serta agrowisata. Lokasi pesisir indah ini menyatu dengan cerita mistis Nyai Roro Kidul serta ekploitasi batu bara di Bayah oleh penjajah asing.

Pantai Ciantir mempunyai pasir putih dengan ombak laun, serta panorama di seputar pantai yang tetap asli. Di pantai ini dapat digunakan untuk berenang, karena murni berpasir, tidak ada karang yang menghalangi. Tanjung Layar juga ikon dari Pantai Sawarna berbentuk dua karang besar yang berhimpitan seperti layar kapal, di sekitarnya terbagi dalam karang-karang cadas serta karang yang datar seakan lantai di suatu kapal.

Di Karang Teraje ini dapat lihat sunset lebih terang. Pantai ini terbagi dalam 
110

M.H. Dewi Susilowati. Potensi Wilayah Sekitar Pantai Selatan Kabupaten Lebak Provinsi Banten Dalam Mendukung Pembangunan Pariwisata

gugusan karang yang menjulang selama pantai, serta menarik untuk seseorang fotografer lanskap untuk dicoba. Gua Lalay yaitu suatu gua yang ada di seputar pematang sawah. Gua ini menghidangkan panorama indah untuk caving di gua-gua.

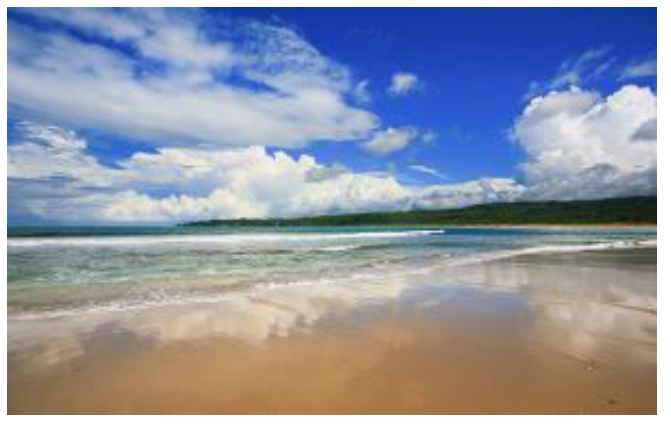

\section{Gambar 1. Pantai Ciantir}

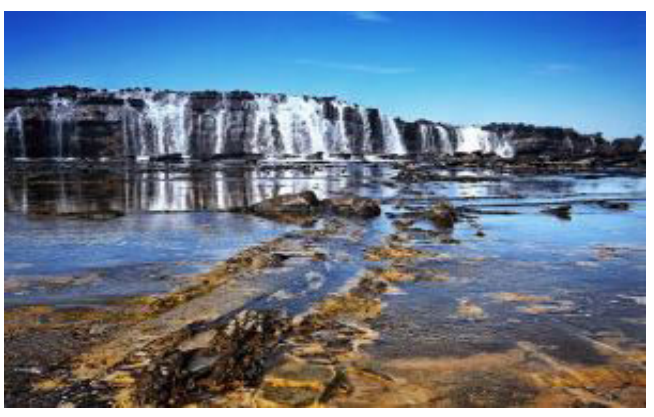

Gambar 2 Karang Teraje

Disamping fasilitas primer yang menarik, didukung pula dengan fasilitas sekunder seperti akomodasi (penginapan), kuliner (rumah makan) sekitar pantai.. Warga setempat di Sawarna yaitu nelayan penangkap ikan kecil, serta ikan teri halus atau terkadang orang kota menamakannya teri medan. Disini teri halus dijual dengan harga murah (kurang dari 5 ribu rupiah dalam bentuk pepes atau digoreng campur terigu.

\section{KESIMPULAN}

Kesimpulan yang diperoleh bahwa:
Potensi wilayah antar desa terdapat variasi, namun sebagian besar merupakan desa yang didominasi oleh perkebunan, jumlah dan kepadatan penduduk rendah hingga sedang, pendidikan penduduk didominasi oleh pendidikan dasar, mata pencaharian didominasi oleh petani dan buruh tani, aksesibilitas relatif sedang hingga rendah.

Secara spasial menunjukkan pengembangan pariwisata lebih diprioritaskan di bagian timur pantai selatan Kabupaten Lebak seperti Desa Sawarna Kecamatan Bayah, yang letaknya lebih dekat dengan pantai Pelabuhanratu Sukabumi yang lebih berkembang dan mempunyai variasi atraksi pariwisata.

\section{DAFTAR RUJUKAN}

Ajala OA \& Aliu IR. 2013. Tourism and Integrated Development: A Geographic Perspective. Geografika Online, Malaysia Journal of Sciety and Space 9 Issue.

Aeni, Eni Nur. 2011. Studi Komparatif Kebijakan Pemerintah Daerah Dalam Program Pemulihan Kembali Daerah Wisata Pantai Pasca Bencana. Jurnal Ilmiah Pariwisata, Juli 2011, Vol. 16 No. 2. Hal $126-141$.

Atkinson, Doreen. 2016. Is'South Africa's Great Karoo Region Becoming a Tourism Destination. Journal of Arid Environments Elsever Ltd.

Akdag, Gurhan \& Zafer Oter. 2011. Assesment of World Tourism from a Geographical Perspective and a Comparative View of Leading Destinations in The Market. Science Direct.: Elsevier Ltd.

Biddulph, Robin. 2015. Limits to Mass Tourism's Effects in Rural. Journal 
Annals of Tourism Research 50 (2015) 98-112.

Burton, R. 2005. Travel Geography. Pitman Publishing. USA.

Fatimah, Titin. 2015. The Impacts of Rural Tourism Initiatives on Cutural Landscape Sustainability in Borobudur Area. Procedia: Social and Behavioral Sciences 216 (2015567 -577)

Gruber, Denis. 2008. Interduction in social Network analysis. Theoretical Approaches and Empirical Analysis with computer-assisted progammes. State University of St. Petersburg. Faculty of Sociology.DAAD.

Gavilan, M.Dolores Sarrion et al. 2015. Spatial Distribution of Tourism Supply in Andalusia. Journal Tourism Mansgement Perspectives 15 (2015) 9-45, Elsevier Ltd.

Johnson, Nuala C. 2016. Where Geography and History Meet: Heritage Tourism and The Big House in Ireland. Taylor \& Francis, Association of American Geographere, This Content Downloaded 11 mar 2016.

Nawawi, Ahmad. 2013. Partisipasi Masyarakat Dalam Pengelolaan Wisata Pantai Depok di Desa Kretek Parangtritis. Jurnal Nasional Pariwisata, Volume 5, Nomor 2, Agustus 2013 (103-109). ISSN: 1411-9862.

Obonyo, George Otieno \& Erick Victor Onyango Fwaya. 2012. Integrating Tourirsm With Rural Development Strategies in Western Kenya. International Journal of Hospitality $\&$ Tourism Systems, Volume 5 Issue 2 Desember 2012. ISSN: 0947-6250 Print.

Susilowati MH.Dewi, Tuty H, Ratna S 2012. Pemetaan Kantong Kemiskinan dan Potensi Wilayah Untuk Pemberdayaan Keluarga Miskin di
Kabupaten Lebak Provinsi Banten. Indonesia: Hibah Stranas,UI

Susilowati MH. Dewi, Tuty H, Ratna S. 2013. Pemberdayaan Keluarga Miskin Melalui Pemanfaatan Lahan dan Pengolahan Hasil Pekarangan. Hibah CEGs UI

Susilowati MH. Dewi, Ratna S. Tito L.I 2009. Pemodelan Struktur Ruang Perkotaan (Studi Kasus Kota Bekasi). DRPM Universitas Indonesia.

Tanaya, Dhayita Rukti dan Iwan Rudiarto, 2014. Potensi Pengembangan Ekowisata Berbasih Masyarakat di Kawasan Rawa Pening, Kabupaten Semarang. Jurnal Teknik PWK Volume 3 Nomer 1, 2014, Online: http://ejournalsl.undip.ac.id/index.p hp/pwk.

Vitasurya, Vincenti Reni. 2015. Local Wisdom for Sustainable Development of Rural Tourism, Case on Kaliburu and Lopati Village, Province of Daerah Istimewa Yogyakarta. Procedia: Social and Behavioral Sciences 216 (2016) $97-108$.

Yoeti ,H. Oka A. 2000. Ekowisata, Pariwisata Berwawasan Lingkungan Hidup. PT. Pertjo. Jakarta.

Zaidah, Esmat. 2016. The Impact of Culture Distance on Local Residence on Local Residents perception of Tourism Development: The Case of Dubai in UAE. Journal of Tourism, vol 64 (1) 109-126.

Zakaria, Faris. 2014. Konsep Pengembangan Kawasan Desa Wisata di Desa Bandungan Kecamatan Pakokng Kabupaten Pamekasan. Journal Teknik Pomits Vol. 3, No 2 (2014) ISSN 23373539 . 